\title{
IMPROVING CONSTRUCTION SAFETY PERFORMANCE FOR EQUIPMENT USING SAFEQUIP
}

\author{
K. M. Shawki, A. M. Ragheb, and H. K. Eliwah \\ Construction and Building Engineering Dept., College of Engineering and Technology, \\ ASTMT, Alexandria, Egypt
}

\begin{abstract}
Accidents occur on construction sites around the world despite various occupational safety and health laws, rules, and regulations. In addition, the traditional method of improving safety performance in construction firms is to implement an effective safety program. For this purpose, a computer model (SAFEQUIP) is designed to assist persons to interact with the construction equipment safely. SAFEQUIP is mainly targeted to give easy and quick reports for engineers and equipment operators in the area of equipment safety. SAFEQUIP provides the engineers and operators with general health and safety precautions, as well as detailed safety recommendations for the most common equipment in the construction field such as excavators, trucks, loaders, dozers, compactors and scrapers.

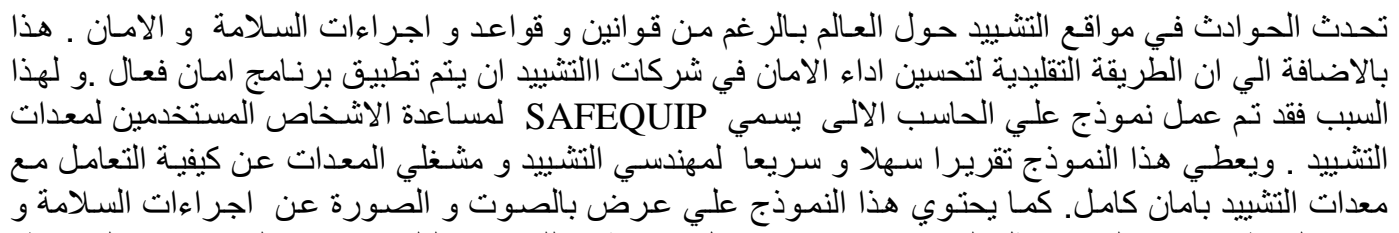

Keywords: Construction; Equipment; Health and Safety.

\section{INTRODUCTION}

People are most often involved in accidents as they walk around the construction site or when they come into contact with equipment in or around the site. It is therefore important to understand the various common accidents causes and the control strategies that can be employed to reduce them. Slips, trips and falls account for the majority of accidents to pedestrians, and the more serious accidents between pedestrians and vehicles can often be traced back to excessive speed or other unsafe vehicle practices, such as lack of driver training. Many of the risk associated with these hazards can be significantly reduced by effective management system (Hughes and Ferrett, 2005).

The U.S. Department of Labor (Bureau of Labor Statistics, 2008) reports an average of one death and 167 injuries per $\$ 100,000,000$ of annual construction spending. The total cost of these accidents reached $\$ 8.9$ billion, or $6.5 \%$ of the $\$ 137$ billion spent annually on industrial, utility and commercial construction (Kartam, 1997). The construction industry is statistically one of the most hazardous industries and ranks low in safety. One out of every six construction workers can expect to be injured every year, at an average cost of $\$ 18,000$. The staggering number translates to more than 2,000 deaths and 200,000 disabling injuries each year (Hinze 1993).

There are numerous factors responsible for health problems and construction site accidents. The five most common categories of accidents defined by Occupational Safety and Health Administration (OSHA) are: falls, struck-by, caught in /between, electric shock, and others (Hinze et al., 1998). OSHA examined the construction fatalities occurring from 1985-1989 in the five categories (OSHA 1990). The results showed that $33 \%$ of the fatalities in construction were caused by falls, $22 \%$ were struckby incidents, $18 \%$ were caught in /between incidents, $17 \%$ were electrocutions, and $10 \%$ were caused by other conditions. In the analysis of these accidents, various factors were found to contribute to accidents. These include severe weather, hazards, substances used or generated during construction, site conditions, unsafe practices (methods, equipment, etc.), inadequate training, poor supervision and monitoring, lack of health and safety facilities, and human errors (Aunmba and Bishop, 1997).

All construction firms need a carefully planned and directed safety program to minimize accidents and to ensure compliance with OSHA and other safety regulations. However, no safety program will be successful without the active support of the top 
management. Job-site supervisors have traditionally neglected safety in their haste to get the job done on time and within budget. Only when supervisors are convinced by higher management that safety is equally as important as production, the benefits of an effective safety program will be achieved. An effective safety program must install a sense of safety consciousness in every employee.

\section{SAFETY FUNDAMENTALS}

The appropriate sections of safety manual identify safety rules for specific equipment. Also, applicable technical and operator manuals must be checked prior to operating all equipment. Some general safety rules are as follows (Nunnally, 1993,2000):

- Inspect of equipment before use, and periodically on a regular basis.

- To ensure that mechanized equipment is operated by qualified and authorized personnel only.

- Using seat belts when they are available.

- Provide barriers to prevent personnel from walking under loading equipment that has a hoist or lift capability.

- Operation of equipment in a manner that will not endanger persons or property.

- Observe safe operating speeds.

- Shut down and turn off the engine when equipment is unattended.

- Stop the equipment completely (apply the parking brake if available) before mounting or dismounting.

- Do not operate any machinery or equipment for more than 10 consecutive hours without an eighthour rest interval.

- Post the safe load capacities at the operator's position on all equipment not rigged to prevent overloading.

- Post the safe operating speeds at the operator's position on all equipment not having a speed governor.

- To ensure that only the operator is on the equipment, while it is running.

- Supervisors can authorize exceptions in emergency situations, some training situations, and when required for maintenance.

- Shut down and turn off the engine when refueling motor vehicles and mechanized equipment.

- Before using a machine, a qualified, licensed operator should inspect and test the equipment to determine its safe operating condition. Equipment operator maintenance checks, service charts, and common sense ensure safe operation and proper maintenance. Tag any unsafe machinery or equipment "Out of Service, Do Not Use" at the operator's position, to prevent its use until repaired. Ensure that the equipment's safety features (backup alarms, lights, and so on) are operational.

For special repair and maintenance procedures, follow these instructions:

- Shut down or lock out equipment controls, while a machine is being repaired, adjusted, or serviced.

- Position the equipment in a place, away from the project area, that is safe for the mechanic to work.

- Crib or block suspended machinery, equipment, or parts, and machines held apart by slings, hoists, or jacks. Do not work underneath or between items not properly blocked.

- Lower blades, bowls, hooks, buckets, and forks to the ground or onto suitable blocking material when equipment is undergoing maintenance or repairs.

When operating equipment at night:

- Equip all mobile equipment with adequate headlights and taillights.

- Keep construction roads and working areas well illuminated until all workers have left the area.

- Ensure that signalers, spotters, inspectors, maintenance personnel, and others who work in dark areas exposed to vehicular traffic wear reflector zed vests or other such apparel if the tactical situation permits.

\section{SAFEQUIP}

A computer model for safety (SAFEQUIP) was designed to facilitate user safety requirements during equipment operation. Microsoft Visual Basic was chosen as the main programming language for SAFEQUIP. The Interface is divided into two sections (Fig. 1). In the first section, the user may find a readable document that is available for printing. In the second section, there are 16 safety media with a one hour lecture per video that can be used as a training source (Fig. 2). These media consist of:

(1) 770-772 Off Highway Truck Operating Tips: these video cover basic tips for the safe operation of the 770 and 772 models off highway trucks.

(2) Shake Hands with Danger: This classic Caterpillar safety video re-enacts numerous accident scenarios and features the infamous accident victim, "Three-Fingered Joe."

(3) 5130/5230 Mass Excavator Operating Orientation: This video reviews the safe 
operation of Caterpillar's 5130/5230 Mass Excavators.

(4) MULTIPLE CHOICE: This classic Caterpillar safety video presents six accident scenarios based on actual accidents, and it asks the viewer to answer questions about what caused each of the accidents.

(5) 700 Series Articulated Trucks Operating Tips: This video covers the basic safe operation of Caterpillar's 700 series Articulated trucks.

(6) E-Series Articulated Truck Operating Tips: This video reviews safe operating techniques for the E Series Articulated Trucks.

(7) Safety Basics: Lockout Tagout: Volume 11 in Caterpillar's Safety Basics video series, this 2008 video demonstrates the safe lockout and tagout procedures for Caterpillar equipment.

(8) Waste Handlers - Machine Walk Around: This video demonstrates a four-step process for machine walk around inspections and shows when to complete the inspections

(9) Fatal Mistakes: This video discusses safety precautions necessary when operating or interacting with Off Highway Trucks.

(10) D350E-D400E Series II Operator Tips: This video reviews safe operating techniques for the D350E and D400E Series II Articulated Trucks.

(11) Safety Basics: Warning Labels: Volume 4 in Caterpillar's Safety Basics video series, this video briefs viewers on the importance of heeding product warning labels, and also reviews how labels are designed to communicate both hazards and the means of avoiding those hazards.

(12) Safety Basics: Seat Belts: Volume 2 in Caterpillar's Safety Basics video series, this video focuses on one of the most basic-yet most important-safety tools available to operators: the seat belt

(13) Safety Basics: Personal Protective Equipment: Volume 5 in Caterpillar's Safety Basics video series, this 2007 video covers what is frequently the last line of defense between you and injury: personal protective equipment, or "PPE.

(14) Safety Basics: Tire Safety: Volume 6 in Caterpillar's Safety Basics video series, this 2007 video emphasizes the importance of proper tire maintenance, and details the critical role that tires play in everyday safety.

(15) Safety Basics: Slips and Falls: Volume 7 in Caterpillar's Safety Basics video series, this 2007 video addresses how to avoid one of the most frequent safety hazards: slips and falls.

(16) Safety Basics: Load and Transport: Volume 9 in Caterpillar's Safety Basics video series, this
2007 video demonstrates the safest ways to load and transport Caterpillar machines.

More safety recommendations for equipment are provided in SAFEQUIP. Figure 3 shows safety precautions for excavator, trucks and loaders, and Figure 4 shows safety recommendations for dozers, compactors and scrapers.

\section{CONCLUSIONS}

In this paper, a review of safety recommendations was made using a computer model (SAFEQUIP). SAFEQUIP gives quick and easy safety recommendations for engineers and equipment operators as it contains general health and safety precautions and covers a wide range of equipment used in the field of construction such as excavators, trucks, loaders, dozers, compactors and scrapers. Following SAFEQUIP recommendations will certainly reduce the accidents resulting from equipment operations and improve the record of health and safety in the construction sites.

\section{REFERENCES}

[1] Hughes, P. and Ed Ferrett (2005) . Introduction to Health and Safety in Construction. ELSEVIER (First edition text book).

[2] Kartam , N. (1997) . Integrating Safety and Health Performance into Construction CPM. . Journal of construction Engineering and Management ,ASCE, Vol-123, No.2 pp0 121126.

[3] Hinze , J. (1993). Constriction Contracts , McGraw-Hill Book Co. ,Inc., New York , N.Y.

[4] Hinze ,J.,Pederson , C., and Fredley , j.(1998) .Indentifying Root Caused of Construction Accidents . Journal of Construction Engineering and Management, ASCE, Vol.124, No1, pp.6771.

[5] Anumba, C., and Bishop, G.(1997) Importance of Safety Considerations in Site Layout and Organization . Canadian Journal of Civil Engineering, Vol.24 No. 2 ,pp.229-236.

[6] Bureau of Labor Statistics (2008) . Census of Fatal Occupational Injuries . Dept. of Labor, Washington,DC,http://stats.bls.gov/iif/oshcfoi1.h tm (accessed on May 12, 2010).

[7] Caterpillar (2006) . Caterpillar Performance Handbook. , 36th Ed., Caterpillar Tractor Company, Peoria, Illinois, USA.

[8] Nunnally, S.W. (1993) .Construction Methods and Management. Prentice Hall, NJ. 
ERJ

Engineering Research Journal

Faculty of Engineering

Minoufiya University

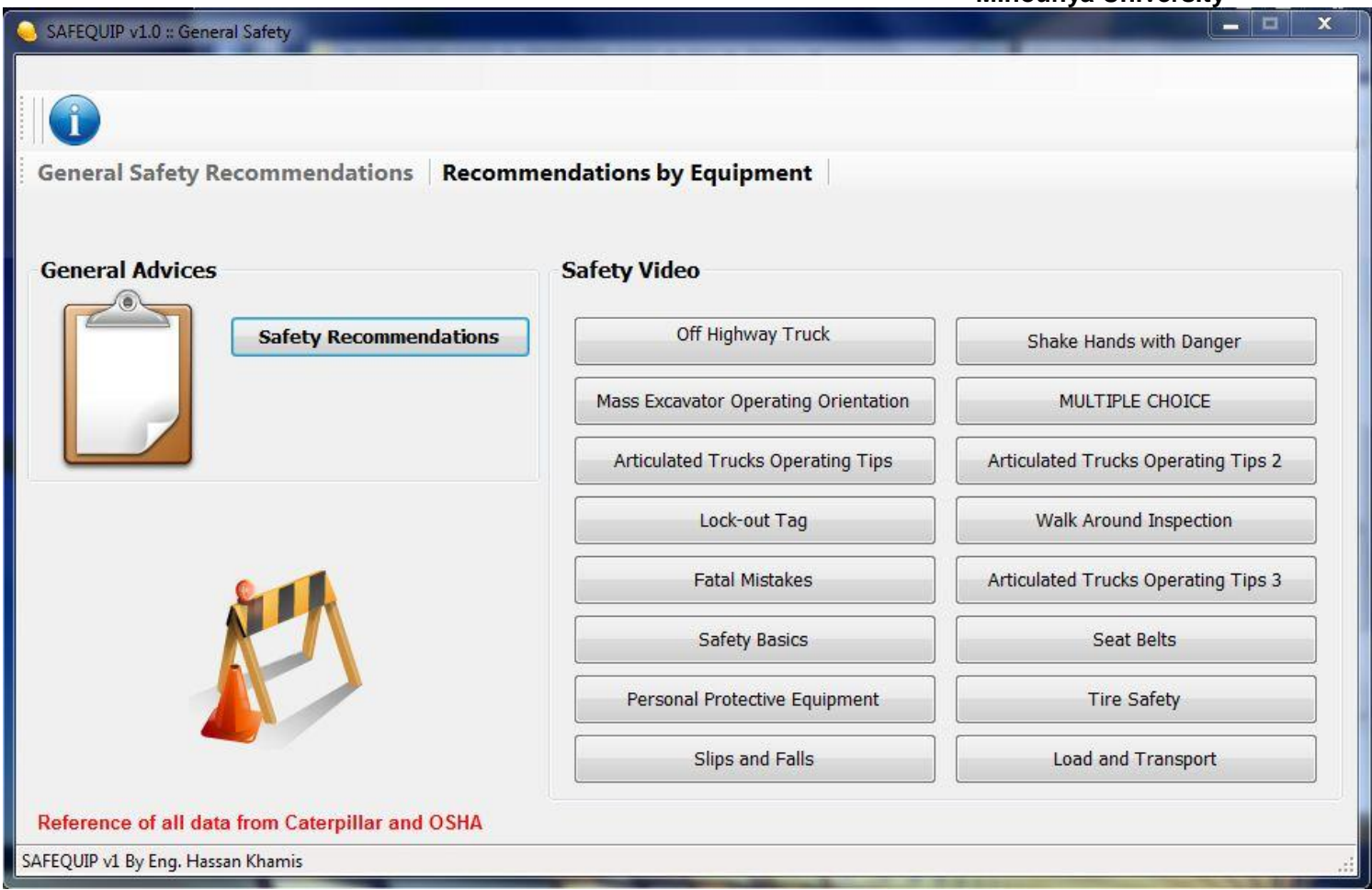

Fig. 1 SAFEQUIP Main Interface

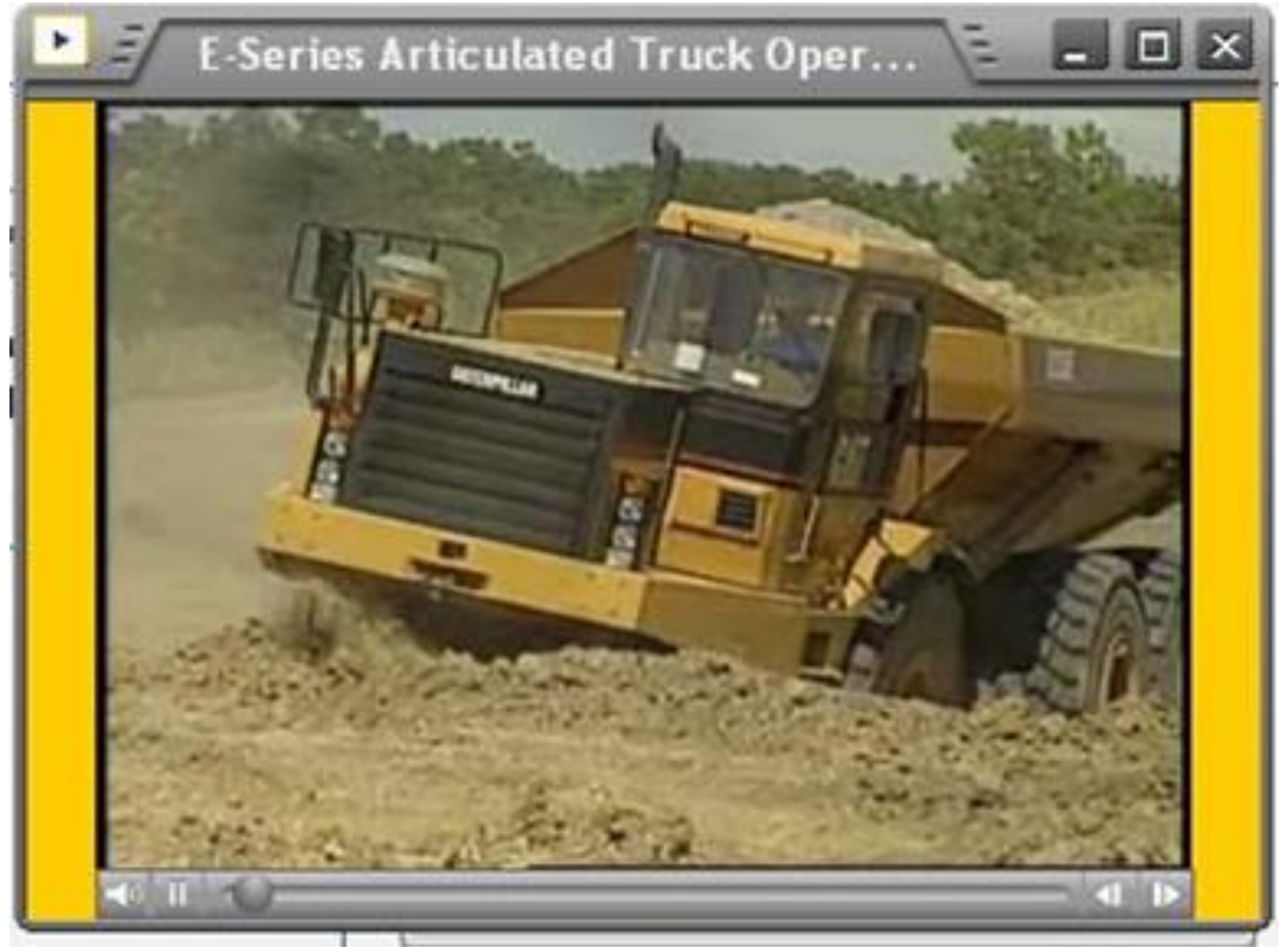

Fig. 2 SAFEQUIP Video Sample

Engineering Research Journal, Vol. 33, No. 4, October 2010, PP: 413-417 


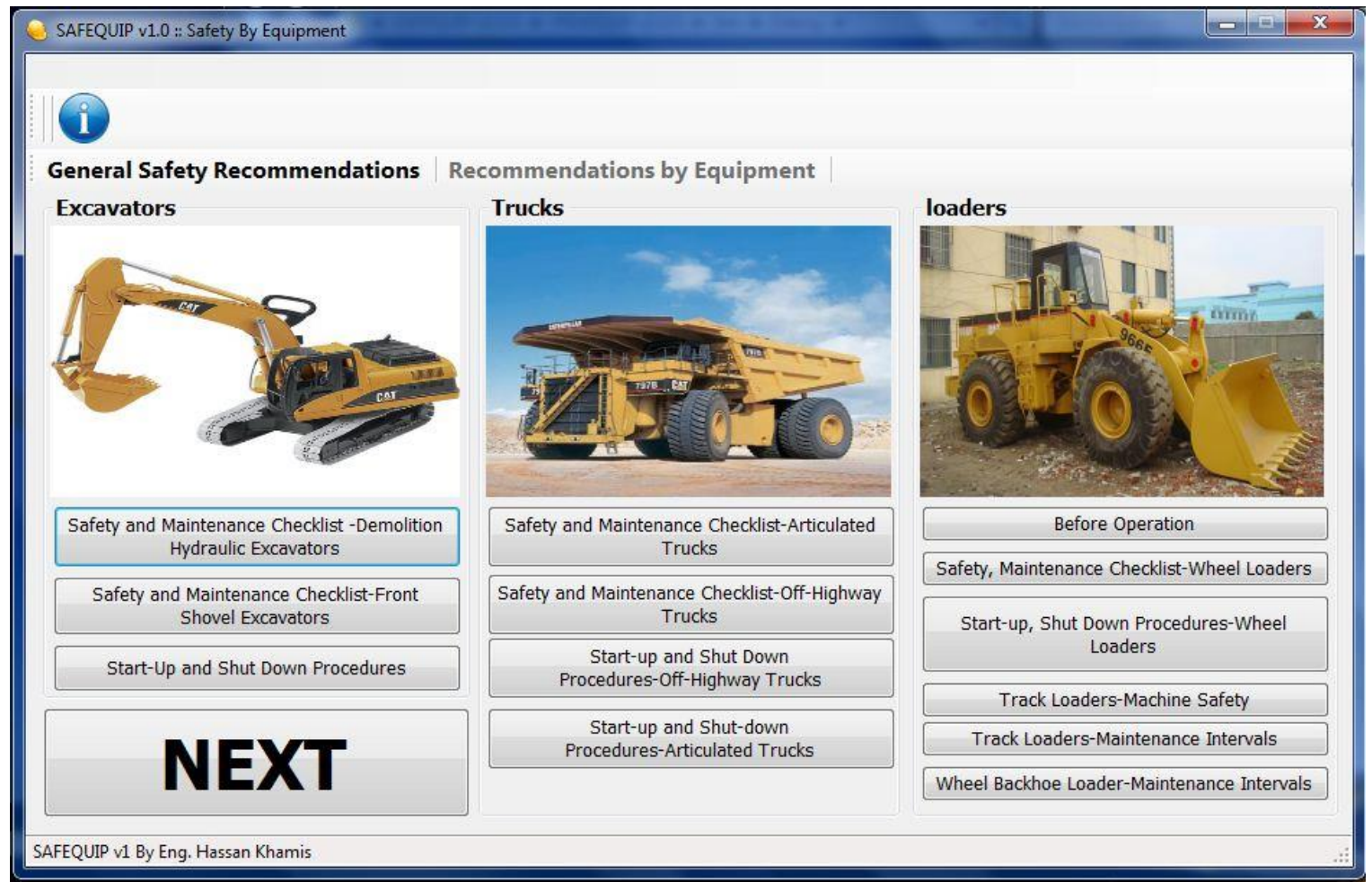

Fig. 3 SAFEQUIP Interface for Excavators, Trucks and Loaders

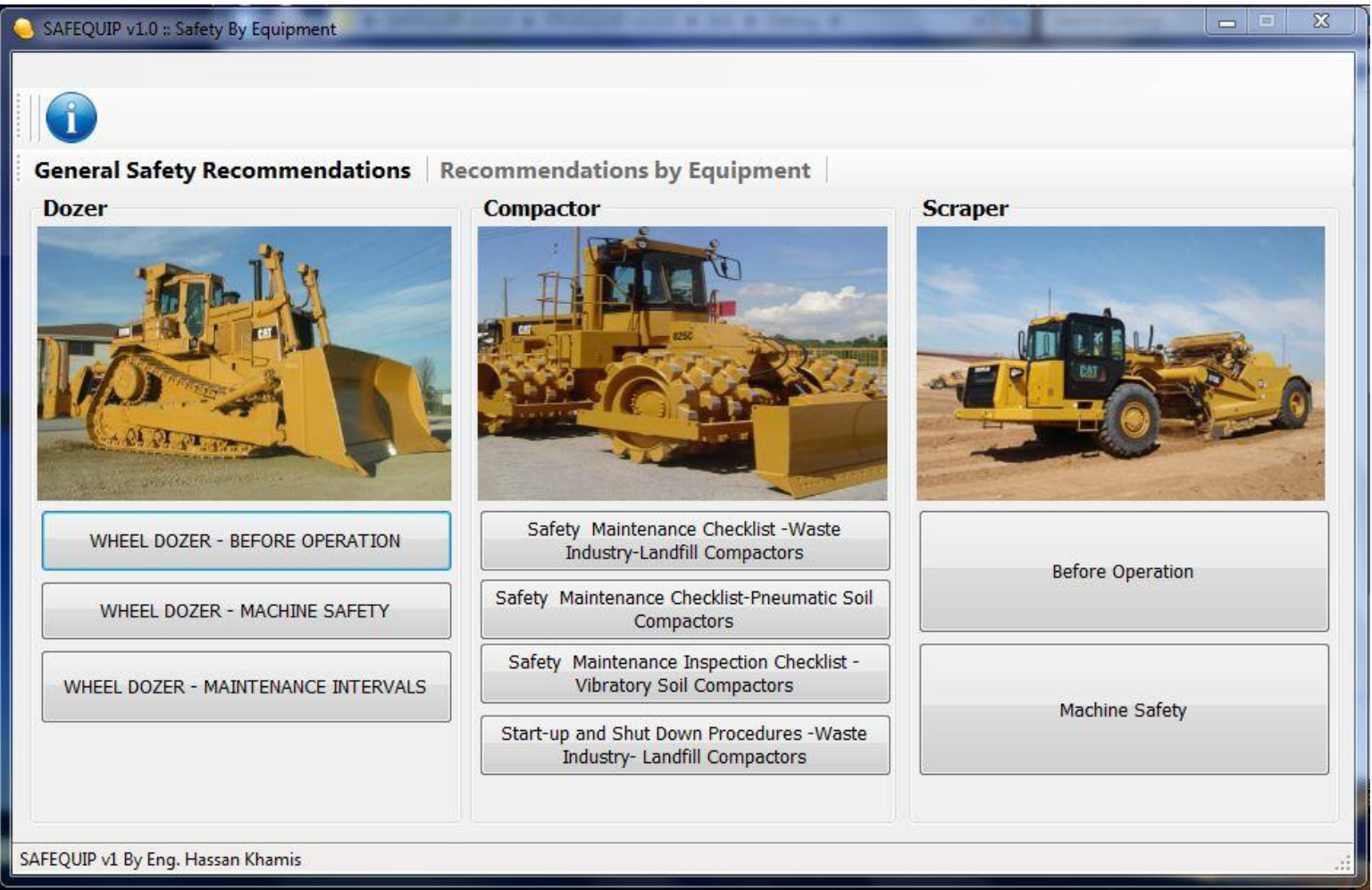

Fig. 4 SAFEQUIP Interface for Dozers, Compactors and Scrapers 